Article

\title{
The In Vitro Analysis of Prebiotics to Be Used as a Component of a Synbiotic Preparation
}

\author{
Katarzyna Śliżewska * and Agnieszka Chlebicz-Wójcik * (B) \\ Institute of Fermentation Technology and Microbiology, Faculty of Biotechnology and Food Sciences, \\ Lodz University of Technology, Wólczańska 171/173, 90-924 Łódź, Poland \\ * Correspondence: katarzyna.slizewska@p.lodz.pl (K.Ś.); agnieszka.chlebicz-wojcik@dokt.p.lodz.pl (A.C.-W.); \\ Tel.: +48-42-6313-481 (K.Ś. \& A.C.-W.)
}

Received: 6 March 2020; Accepted: 29 April 2020; Published: 30 April 2020

\begin{abstract}
Prebiotics are food components that are selectively fermented by beneficial microbiota and which confer a health benefit. The aim of the study was to select a prebiotic for the chosen probiotic strains to create a synbiotic. The impact of prebiotics (inulin, maltodextrin, corn starch, $\beta$-glucan, and apple pectin) on five Lactobacillus spp. strains' growth and metabolites synthesis (lactic, acetic, propionic, and butyric acids, ethanol, and acetaldehyde) was tested by the plate count method and by high-performance liquid chromatography, respectively. Moreover, the differences in the ratio of $\mathrm{D}(-)$ and $\mathrm{L}(+)$ lactate isomers produced by Lactobacillus spp., as well as variations in the probiotics' enzymatic profiles associated with the prebiotic used for cultivation, were determined with a Megazyme rapid assay kit and API ${ }^{\circledR}$ ZYM assay, accordingly. Finally, the influence of the carbon source (prebiotic) used on the antagonistic activity of the probiotic strains towards pathogenic bacteria, such as Salmonella spp. or Listeria monocytogenes was analyzed in the co-cultures. The results showed that the growth, metabolic profile, and antagonistic activity of the probiotics towards selected pathogens were the most favorable when $2 \%(w / v)$ of inulin was used. Therefore, the combination of inulin with selected probiotics is a promising synbiotic mixture.
\end{abstract}

Keywords: probiotics; prebiotics; inulin; synbiotics; microbial growth; metabolic activity; antagonism

\section{Introduction}

Probiotics are defined as live strains of strictly selected microorganisms which, when administered in adequate amounts, confer a health benefit on the host [1]. On the other hand, in 1995, Glenn Gibson and Marcel Roberfroid introduced the concept of prebiotics, which were described as a "non-digestible food ingredient that beneficially affects the host by selectively stimulating the growth and/or activity of one or a limited number of bacteria in the colon, and thus improves host health" [2]. The International Scientific Association of Probiotics and Prebiotics (ISAPP) presented a new definition of a prebiotic in 2016, which characterized it as "a substrate that is selectively utilized by host microorganisms conferring a health benefit" [3].

Prebiotics are known for their positive effect on not only human but also animal health [4]. In order to define a carbohydrate as a prebiotic, in addition to being fermented by microorganisms, the compound should exhibit resistivity towards mammalian gastric enzymes and the acidity of the stomach [5]. On the other hand, prebiotics must be susceptible to the enzymes synthesized by bacteria residing in the colon [6]. What makes them different from other dietary fiber, such as xylans, and cellulose is that prebiotics favor the growth of only the beneficial microorganisms [7]. As a result of the prebiotics' degradation, short-chain fatty acids (SCFAs) are produced, which is a desirable feature. SCFAs are organic acids which have fewer than six carbons in the chain, and the gastrointestinal tract (GIT) microbiota most commonly produce acetic, propionic, and butyric acids [8,9]. These short, 
volatile fatty acids can enter the bloodstream through enterocytes and can be metabolized in the brain or muscle tissue (acetate) or be utilized in the liver, interfering with cholesterol production or serving as the energy source for the GIT cells (butyric acid). Apart from this indirect mode of action, prebiotics can also modulate host health directly through GIT microbiota modulation [9-11]. Moreover, researchers have proven in both human and animal models that prebiotics could also hinder the attachment of pathogens to epithelial cells, have an impact on the secretion of the peptides responsible for appetite regulation, improve the absorption of minerals, and diminish the risk of colon cancer [12].

Besides probiotics and prebiotics being widely used, synbiotics are studied for their beneficial effect on host health. Synbiotics combine the pro- and prebiotic components in such a way that they act synergistically. In such preparations, prebiotics not only stimulate the growth of the beneficial microorganisms which already reside in the GIT, but they also enhance the survival of the included probiotics $[13,14]$.

The following research aimed to compare the prebiotic potential of five substances-inulin, maltodextrin, corn starch, apple pectin, and $\beta$-glucan-in order to select the carbohydrate component for the creation of a synbiotic preparation with the previously selected probiotics. The impact of the carbohydrates on the growth of probiotics, SCFAs production, and antagonistic activity was assessed because these aspects are of vital importance to the prebiotic mechanism of action [15]. Moreover, the potentially negative effects of the selected carbohydrates were evaluated in comparison to glucose, by determining the concentrations of synthesized ethanol and acetaldehyde, and by characterizing the enzymatic profile. The described in vitro screening of the prebiotics poses as a valid basis for developing new synbiotic preparation, whose beneficial effect could be further studied in vivo.

\section{Materials and Methods}

\subsection{Prebiotic Substances}

Five different substances were analyzed for their prebiotic features: inulin from chicory roots (INU; Orafti ${ }^{\circledR}$ HSI; BENEO-Orafti S.A., Oreye, Belgium), maltodextrin (MD; Sigma-Aldrich, St. Louis, MI, USA), apple pectin (AP; Sigma-Aldrich, St. Louis, Missouri, USA), 1,3/1,6 D ß-glucan from brewer's yeast (BG; Hepatica, Niemce, Poland) and corn starch (CS; RADIX-BIS Sp. z o.o., Rotmanka, Poland). For each analysis, glucose (GLU; Sigma-Aldrich, St. Louis, Missouri, USA) was used as the reference substance.

\subsection{Microorganisms and Inoculum Preparation}

The prebiotic effect was analyzed on 5 Lactobacillus spp. strains (Table 1), which were isolated with the use of Rogosa agar (BD Difco ${ }^{\mathrm{TM}}$, Sparks, NV, USA) from plant silage or the gastrointestinal tracts of monogastric animals within project no. PBS3/A8/32/2015.

Table 1. Probiotic strains.

\begin{tabular}{cc}
\hline Strains & Source \\
\hline Lb. paracasei ŁOCK 1091 & Caecal content of sow \\
Lb. pentosus ŁOCK 0860 & Broiler chicken dung \\
Lb. plantarum ŁOCK 0860 & Plant silage \\
Lb. reuteri ŁOCK 1092 & Piglet's caecal content \\
Lb. rhamnosus ŁOCK 1087 & Turkey dung \\
\hline
\end{tabular}

The strains are on deposit and can be purchased from the Łodź Collection of Pure Cultures (ŁOCK 105) of the Institute of Fermentation Technology and Microbiology, Łodź University of Technology [16]. The probiotic characteristics of selected strains of Lactobacillus spp. were previously described and are the subjects of patent applications [17-21].

In addition to that, four pathogenic strains were used: Salmonella enterica subsp. enterica serovar Typhimurium ATCC 13311, Salmonella enterica subsp. enterica serovar Enteritidis ATCC 13076, 
Salmonella enterica subsp. enterica serovar Choleraesuis PCM 2565, and Listeria monocytogenes ATCC 13932. The strains were obtained from the American Type Culture Collection (ATCC; Manassas, VA, USA) and the Polish Collection of Microorganisms (PCM; Wrosław, Poland).

All strains were stored in Cryobanks ${ }^{\mathrm{TM}}$ (Copan Diagnostics Inc., Murrieta, CA, USA) at $-22{ }^{\circ} \mathrm{C}$. Before analysis, both the probiotic and pathogenic strains were activated and passaged twice in de Man, Rogosa, and Sharpe broth (MRS; Merck Millipore, Darmstadt, Germany) or Nutrient broth (Merck Millipore), accordingly, at $37^{\circ} \mathrm{C}$ for $24 \mathrm{~h}$, without oxygen limitation.

To prepare the inoculum, cells of each activated strain were washed twice in PBS (Calbiochem ${ }^{\circledR}$, Merck Millipore) by centrifuging at 3468× $g$ RCF (Centrifuge MPW-350R; MPW Med. Instruments, Warsaw, Poland) for $10 \mathrm{~min}$, and afterward being re-suspended in PBS. A final optical density (OD) was set at a wavelength of $600 \mathrm{~nm}$ to values, which corresponded to the $1 \times 10^{8}$ and $1 \times 10^{7}$ colony-forming units per milliliter $(\mathrm{CFU} / \mathrm{mL})$ of probiotics and pathogens, respectively, based on previously prepared standard curves for each strain.

\subsection{Growth of Selected Lactobacillus spp. Strains in the Presence of Prebiotics}

Prebiotic impact on the Lactobacillus spp. strains' growth was analyzed for five substances, namely, inulin, maltodextrin, corn starch, apple pectin, and $\beta$-glucan. The results were compared to the probiotic bacteria growth in the presence of glucose.

The prepared bacterial solutions of Lactobacillus spp. strains' monocultures were added as $10 \%$ $(v / v)$ inoculum to MRS broths, in which glucose was substituted with each prebiotic separately in concentrations of $1.0 \%, 1.5 \%$, and $2.0 \%(w / v)$. MRS broths with $1.0 \%, 1.5 \%$, and $2.0 \%(w / v)$ of glucose were used as the control medium. The cultures were incubated for $48 \mathrm{~h}$ at $37^{\circ} \mathrm{C}$.

Subsequently, the serial dilutions were prepared, and the number of Lactobacillus spp. were determined with the use of the pour plate method in MRS agar after $48 \mathrm{~h}$ of incubation at $37^{\circ} \mathrm{C}$. Each culture was conducted in three repetitions and the results are presented as the CFU/mL.

\subsection{Identification of Metabolites Produced by the Probiotic Lactobacillus spp. in the Process of Prebiotics Fermentation}

The products of prebiotics fermentation by Lactobacillus spp. strains, namely, lactic acid, SCFAs (acetic, propionic, and butyric acids), acetaldehyde, and ethanol, were determined using high-performance liquid chromatography analysis (HPLC) on a liquid chromatograph Surveyor (Thermo Fisher Scientific Inc., Waltham, MA, USA).

Inoculums $(10 \% v / v)$ of the probiotic strains' monocultures were introduced into MRS medium with $1.0 \%, 1.5 \%$, and $2.0 \%(w / v)$ of each prebiotic separately, as well as into MRS with an adequate concentration of glucose for the comparison. The strains were cultivated at $37^{\circ} \mathrm{C}$ for $24 \mathrm{~h}$ without oxygen limitation. Subsequently, the samples were centrifuged for $10 \mathrm{~min}$ at $3468 \times g \mathrm{RCF}$, and $0.22 \mu \mathrm{m}$ PTFE syringe filters (Millex-GS; Merck Millipore, Darmstadt, Germany) were used to filter them. Subsequently, $10 \mu \mathrm{L}$ of each sample was injected into an Aminex HPX-87H column with a dimension of $300 \times 7.8 \mathrm{~mm}$ (Bio-Rad Laboratories Inc., Des Plaines, IL, USA) by the loop dispensing valve with a syringe, which was used as an autosampler. The analysis was performed at $60{ }^{\circ} \mathrm{C}$ for 35 min per sample and $0.005 \mathrm{M}$ of $\mathrm{H}_{2} \mathrm{SO}_{4}$ was used as a mobile phase (flow level: $0.6 \mu \mathrm{L} / \mathrm{min}$ ).

The identification of the metabolites was performed in the chromatograms by comparing the retention times to the reference standards used to prepare standard curves. However, their concentrations were calculated based on the area underneath a specific peak. The analysis of each strain cultivated in the presence of different carbon sources was conducted three times.

\subsection{Enzymatic Identification of Optically Active Forms of Lactic Acid}

A D-/L-Lactic Acid (D-/L-Lactate) (Rapid) Assay Kit (Megazyme, Bray, Ireland) was used to assess the ratio of each of the optically active forms of lactic acid. The test was performed in accordance with the manual provided by the manufacturer. 
Briefly, monocultures of selected strains' inoculums $(10 \% v / v)$ were cultivated in the MRS liquid medium in which glucose was replaced with $2 \%(w / v)$ of each of the prebiotic substances. Each strain's monoculture grown in MRS liquid medium with $2 \%(w / v)$ glucose was used as the reference samples. The cultivation process was conducted at $37^{\circ} \mathrm{C}$ for $24 \mathrm{~h}$. Subsequently, the cultures were centrifuged for $10 \mathrm{~min}$ at $3468 \times g \mathrm{RCF}$, and the supernatants $(50 \mu \mathrm{L})$ were submitted for analysis. Next, the $750 \mu \mathrm{L}$ of sterile distilled water was added to each supernatant, as well as the solutions included in the test kit, such as a buffer $(250 \mu \mathrm{L})$, NAD+ solution $(50 \mu \mathrm{L})$, and D-GPT $(10 \mu \mathrm{L})$. After 3 min of incubation, the optical density was measured $\left(\mathrm{OD}_{1}\right)$ and the D-LDH $(10 \mu \mathrm{L})$ was added. Samples were incubated for a further $5 \mathrm{~min}$, and afterward, the $\mathrm{OD}_{2}$ was determined. Subsequently, $10 \mu \mathrm{L}$ of L-LDH was added and the $\mathrm{OD}_{3}$ of the samples was measured after $10 \mathrm{~min}$ of incubation.

Each sample was analyzed in three repetitions and the fraction of D- and L-lactic acid was calculated based on the Equation (1):

$$
\mathrm{c}=0.3204 \times \Delta \mathrm{OD}_{\mathrm{D}}+0.3232 \times \Delta \mathrm{OD}_{\mathrm{L}}
$$

where " $\mathrm{c}$ " represents the total concentration of lactic acid, " $0.3204 \times \Delta \mathrm{OD}_{\mathrm{D}}$ " stands for the D-lactic acid concentration, and " $0.3232 \times \Delta \mathrm{OD}_{\mathrm{L}}$ " is the amount of the $\mathrm{L}(+)$ isomer, and where $\Delta \mathrm{OD}_{\mathrm{D}}=\mathrm{OD}_{2}-$ $\mathrm{OD}_{1}$ and $\Delta \mathrm{OD}_{\mathrm{L}}=\mathrm{OD}_{3}-\mathrm{OD}_{2}$.

\subsection{Enzymatic Profile of Probiotic Lactobacillus spp. in the Presence of Prebiotics}

An API ${ }^{\circledR}$ ZYM test kit (bioMérieux; Marcy l’Etoile, France) was used to establish differences in the enzymatic profile of probiotic Lactobacillus spp. strains depending on the carbon source used, such as prebiotics compared with glucose. The analysis was conducted according to the manual provided by the manufacturer of the test.

Monocultures of the selected strains were grown on MRS slants with each of the prebiotics separately or glucose comparatively at a concentration of $2 \%(w / v)$. The cultivation was conducted at $37^{\circ} \mathrm{C}$ for $48 \mathrm{~h}$. Afterward, the monocultures were suspended in sterile saline solution at a final density between 5 and 6 on McFarland's scale. Each of the prepared bacterial suspensions was introduced individually into all microtubes of the API ${ }^{\circledR} \mathrm{ZYM}$ test strip and incubated at $37^{\circ} \mathrm{C}$ for $4 \mathrm{~h}$. Next, ZYM $A$ and $Z Y M B$ reagents were added to every microtube and the test strips were exposed to light.

Every sample was analyzed in three repetitions and the positive results were obtained based on the color changes visible in the microtubes.

\subsection{The Influence of the Prebiotics on the Antagonistic Activity of Lactobacillus spp. Strains towards Pathogenic Bacteria}

The ability of the selected Lactobacillus spp. strains to inhibit the growth of pathogenic bacteria, namely $S$. Typhimurium, S. Enteritidis, S. Choleraeusis, and L. monocytogenes, was evaluated in co-cultures with the plate count method.

Monocultures of each probiotic or pathogenic strain were propagated in the MRS liquid medium or nutrient broth, respectively, with $2 \%(w / v)$ of the prebiotic substance, or glucose for comparison. The strains were cultivated at $37^{\circ} \mathrm{C}$ for $24 \mathrm{~h}$ without oxygen limitation. Afterward, the bacterial monocultures grown on specific prebiotic were mixed in the amount of $1 \mathrm{~mL}$ of cultures of all probiotic strains with each pathogen separately. An initial number of bacteria was assessed by preparing serial decimal dilutions of each mixture, which were then used in the pour plate technique with MRS agar, Salmonella Shigella agar (SS agar; Merck Millipore), and PALCAM agar (Merck Millipore) for probiotics, Salmonella spp., and L. monocytogenes, respectively. Next, the co-cultures of probiotics and pathogens were incubated at $37^{\circ} \mathrm{C}$ without oxygen limitation.

The changes in the bacterial count were evaluated after $4,8,12$, and $24 \mathrm{~h}$ as it was previously done, in order to determine the initial number of bacteria. The plates were incubated at $37^{\circ} \mathrm{C}$ for $24 \mathrm{~h}$ and the results are presented in $\mathrm{CFU} / \mathrm{mL}$. Each co-culture was conducted in three repetitions. 


\subsection{Statistical Analysis}

Each of the statistical analysis was performed with XLSTAT Software (Addinsoft, SARL, Paris, France). The influence of the prebiotics on the growth performance of selected strains was analyzed with a multi-way analysis of variances (ANOVA) followed by post hoc Tukey's test. Before the ANOVA, the data were checked for normal distribution with the Shapiro-Wilk test, and for the homogeneity of variances with Bartlett's test. On the other hand, the correlation between the prebiotic used and the concentrations of metabolites produced by probiotic strains in the process of fermentation was checked with Principal Component Analysis (PCA) and is presented in the form of biplots including categorical variables and observations. Furthermore, the concentration differences of lactic acid isomers synthesized by the selected strains in the presence of chosen prebiotics were analyzed with the multi-way Welch-ANOVA test because the variances were not homogenous.

\section{Results}

\subsection{Growth of Selected Lactobacillus spp. Strains in the Presence of Prebiotics}

Selected Lactobacillus spp. strains showed similar growth in the presence of three different concentrations $(1.0,1.5$, and $2.0 \% w / v)$ of 5 prebiotic substances, as well as when the glucose was used comparatively as the carbon source (Table 2 ). The abundance of probiotic strains varied between $7.53 \pm 1.28 \log \mathrm{CFU} / \mathrm{mL}$ and $11.09 \pm 0.47 \log \mathrm{CFU} / \mathrm{mL}$. However, the numbers of Lb. rhamnosus ŁOCK 1087, $L b$. reuteri ŁOCK 1092, and Lb. plantarum ŁOCK 0860 were significantly higher when inulin was used as the carbon source at a concentration of $2 \%(w / v): 10.71 \pm 0.81,11.09 \pm 0.47$, and $10.91 \pm 0.92 \log$ $\mathrm{CFU} / \mathrm{mL}$, respectively. A similar dependency was observed when $1.5 \%(w / v)$ of apple pectin was used for the cultivation of $L b$. pentosus ŁOCK $1094(10.84 \pm 0.15 \log$ CFU/mL).

Table 2. The effect of the carbon source on the growth of Lactobacillus spp. strains.

\begin{tabular}{|c|c|c|c|c|c|c|}
\hline \multirow{2}{*}{ 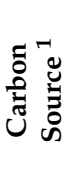 } & \multirow{2}{*}{ 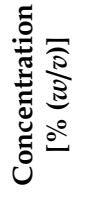 } & \multicolumn{5}{|c|}{ Lactobacillus spp. Strain $[\log \mathrm{CFU} / \mathrm{mL}]^{2}$} \\
\hline & & $\begin{array}{r}\text { rhamnosus } \\
\text { ŁOCK } 1087\end{array}$ & $\begin{array}{c}\text { paracasei } \\
\text { ŁOCK } 1091\end{array}$ & $\begin{array}{c}\text { reuteri ŁOCK } \\
1092\end{array}$ & $\begin{array}{l}\text { plantarum } \\
\text { ŁOCK } 0860\end{array}$ & $\begin{array}{l}\text { pentosus } \\
\text { ŁOCK } 1094\end{array}$ \\
\hline \multirow{3}{*}{ GLU } & 1.0 & $8.00 \pm 1.19^{a, b, c}$ & $7.71 \pm 1.03^{a, b}$ & $7.53 \pm 1.28^{a}$ & $7.99 \pm 1.06^{a, b, c}$ & $8.55 \pm 1.14$ \\
\hline & 1.5 & $9.17 \pm 0.73$ & $8.59 \pm 0.78$ & $8.19 \pm 0.72$ & $8.52 \pm 0.56$ & $8.44 \pm 0.77$ \\
\hline & 2.0 & $10.06 \pm 0.68$ & $10.50 \pm 0.50$ & $8.53 \pm 0.84$ & $9.70 \pm 1.09$ & $9.98 \pm 0.71$ \\
\hline \multirow{3}{*}{$\mathrm{MD}$} & 1.0 & $9.44 \pm 0.93$ & $9.89 \pm 0.64$ & $8.93 \pm 1.34$ & $9.74 \pm 0.98$ & $8.79 \pm 0.70$ \\
\hline & 1.5 & $9.70 \pm 0.75$ & $9.91 \pm 1.03$ & $9.49 \pm 0.89$ & $10.54 \pm 0.50^{b, c, d}$ & $9.83 \pm 0.46$ \\
\hline & 2.0 & $9.80 \pm 0.97$ & $10.37 \pm 0.54$ & $10.05 \pm 0.56$ & $10.38 \pm 0.89$ & $9.64 \pm 1.15$ \\
\hline \multirow{3}{*}{ INU } & 1.0 & $9.02 \pm 0.84$ & $9.43 \pm 0.60$ & $10.37 \pm 0.52$ & $10.15 \pm 0.82$ & $9.70 \pm 1.04$ \\
\hline & 1.5 & $9.20 \pm 1.37$ & $9.61 \pm 0.92$ & $11.04 \pm 0.37^{\mathrm{d}}$ & $10.48 \pm 0.80$ & $10.08 \pm 1.06$ \\
\hline & 2.0 & $10.91 \pm 0.92^{\mathrm{c}, \mathrm{d}}$ & $10.46 \pm 0.59$ & $11.09 \pm 0.47^{\mathrm{d}}$ & $10.71 \pm 0.81^{\mathrm{c}, \mathrm{d}}$ & $10.38 \pm 1.14$ \\
\hline \multirow{3}{*}{ CS } & 1.0 & $8.74 \pm 0.30$ & $8.24 \pm 0.78$ & $8.24 \pm 0.63$ & $9.58 \pm 0.80$ & $8.42 \pm 0.67$ \\
\hline & 1.5 & $9.60 \pm 0.89$ & $8.99 \pm 0.46$ & $9.55 \pm 0.80$ & $10.18 \pm 0.59$ & $9.68 \pm 1.14$ \\
\hline & 2.0 & $10.10 \pm 0.72$ & $9.00 \pm 1.01$ & $9.26 \pm 1.18$ & $10.38 \pm 0.69$ & $9.47 \pm 1.00$ \\
\hline \multirow{3}{*}{$\mathrm{AP}$} & 1.0 & $8.92 \pm 1.04$ & $9.57 \pm 0.87$ & $10.01 \pm 0.29$ & $10.14 \pm 0.72$ & $10.12 \pm 1.06$ \\
\hline & 1.5 & $9.43 \pm 0.71$ & $9.70 \pm 0.75$ & $10.51 \pm 0.57$ & $10.55 \pm 0.76^{b, c, d}$ & $10.84 \pm 0.15^{\text {c.d }}$ \\
\hline & 2.0 & $9.86 \pm 0.85$ & $9.93 \pm 1.01$ & $9.93 \pm 1.01$ & $10.12 \pm 1.10$ & $9.90 \pm 1.20$ \\
\hline \multirow{3}{*}{ BG } & 1.0 & $8.33 \pm 1.05$ & $9.43 \pm 0.62$ & $8.64 \pm 0.84$ & $8.44 \pm 0.80$ & $8.97 \pm 0.67$ \\
\hline & 1.5 & $9.23 \pm 0.67$ & $9.41 \pm 0.75$ & $9.24 \pm 1.29$ & $9.02 \pm 0.74$ & $8.85 \pm 1.15$ \\
\hline & 2.0 & $9.21 \pm 0.97$ & $10.33 \pm 0.46$ & $9.88 \pm 0.32$ & $10.12 \pm 0.57$ & $9.43 \pm 0.80$ \\
\hline
\end{tabular}

${ }^{1}$ Carbohydrates used for the strains culture: GLU-glucose, MD-maltodextrin, INU-inulin, CS-corn starch, AP-apple pectin, and BG- $\beta$-glucan. ${ }^{2}$ Lowercase letters $(a-d)$ represent significantly different mean values, which were determined by multi-way ANOVA $(p<0.05)$ followed by post hoc Tukey's test. The analysis included the impact of all categorical variables, namely, the probiotic strain, the type of prebiotic, and its concentration, as well as their interaction on the results. For clear data presentation, values that were similar to other results showed in the table, and should be categorized as "a,b,c,d" were left unlabeled. 


\subsection{Identification of Metabolites Produced by the Probiotic Lactobacillus spp. in the Process of Prebiotics Fermentation}

Predominantly, the selected strains produced lactic, acetic, and propionic acids in the fermentation process of prebiotics and glucose. Nonetheless, butyric acid, acetaldehyde, and ethanol were also detected, although in substantially lower concentrations. Concentrations of the metabolites depended on the amount and type of carbon source used in the cultivation of probiotic monocultures (Figure 1).

The highest concentrations of lactic acid were observed when the strains were grown in the presence of $2 \%(w / v)$ inulin: the average amount was $30.71 \mu \mathrm{mol} / \mathrm{mL}$ (Figure 1a,c,e,g,i). Furthermore, increased secretion of SCFAs, namely acetic, propionic, and butyric acids, was observed; these compounds were produced in average concentrations of $21.29,17.96$, and $3.08 \mu \mathrm{mol} / \mathrm{mL}$, respectively. These results indicate an enhancement of SCFAs production exceeding $20 \%$ due to usage of $2 \%(w / v)$ inulin as the carbon source in comparison to a similar concentration of glucose. Moreover, the data showed a high negative correlation between using inulin for the cultivation of the probiotic strains and ethanol, as well as acetaldehyde synthesis, which was the opposite for glucose (Figure 1b,d,f,h,j).

An unfavorable influence of the rest of the prebiotics studied, namely, maltodextrin, corn starch, apple pectin, and $\beta$-glucan, on the production of lactic acid and SCFAs by the probiotic strains was observed. A negative correlation between these prebiotics and lactic acid, as well as SCFAs, production was noted (Figure 1).

It was observed that the most beneficial concentration of all prebiotics in terms of growth and metabolism was the $2 \%(w / v)$, which is why this concentration of carbohydrates was used in the further analysis.

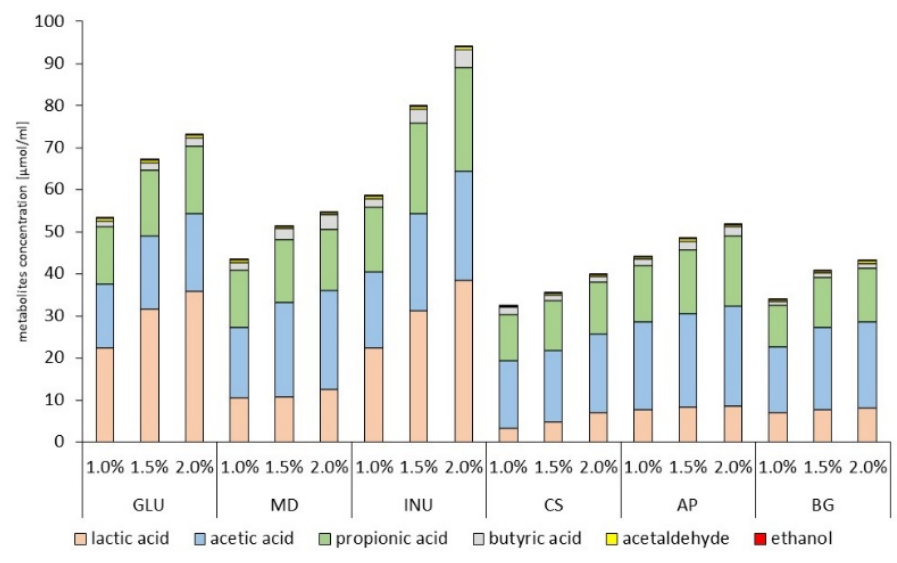

(a)

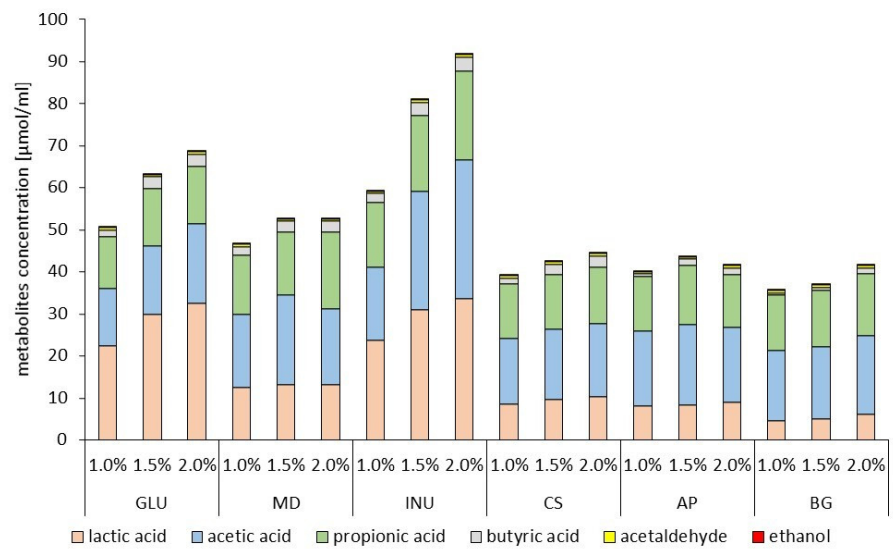

(c)

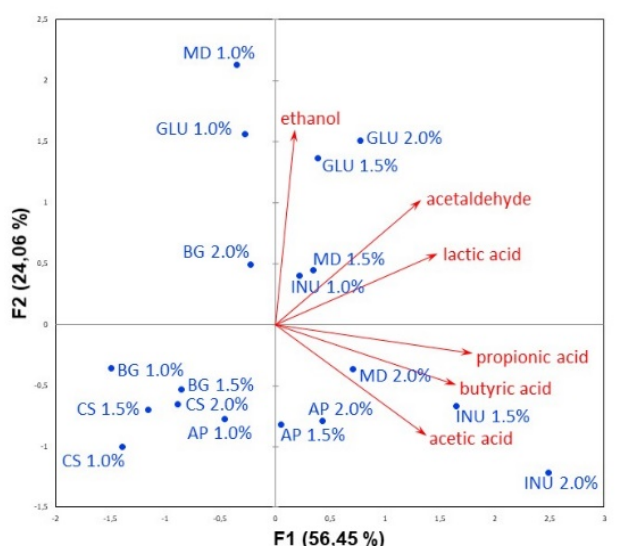

(b)

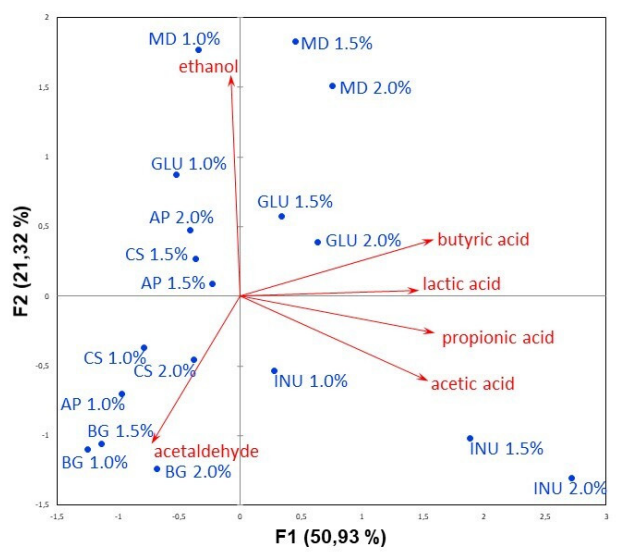

(d)

Figure 1. Cont. 


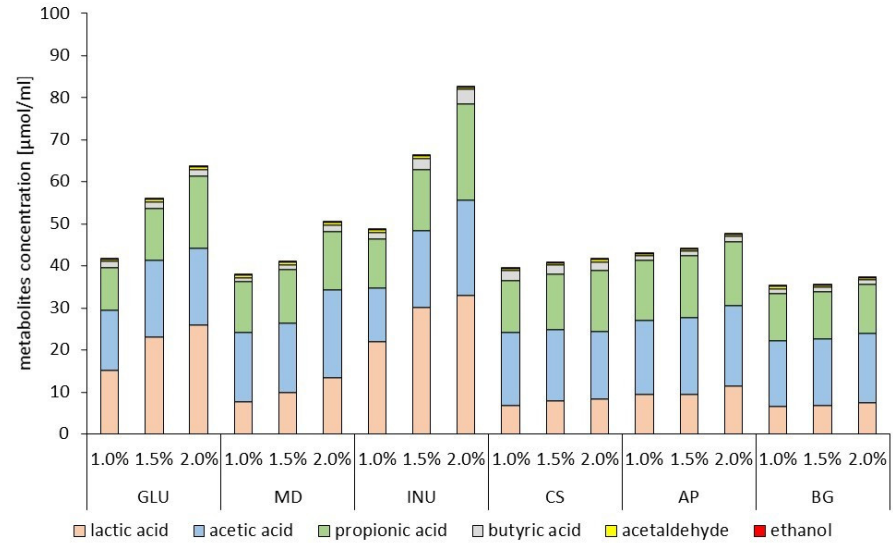

(e)

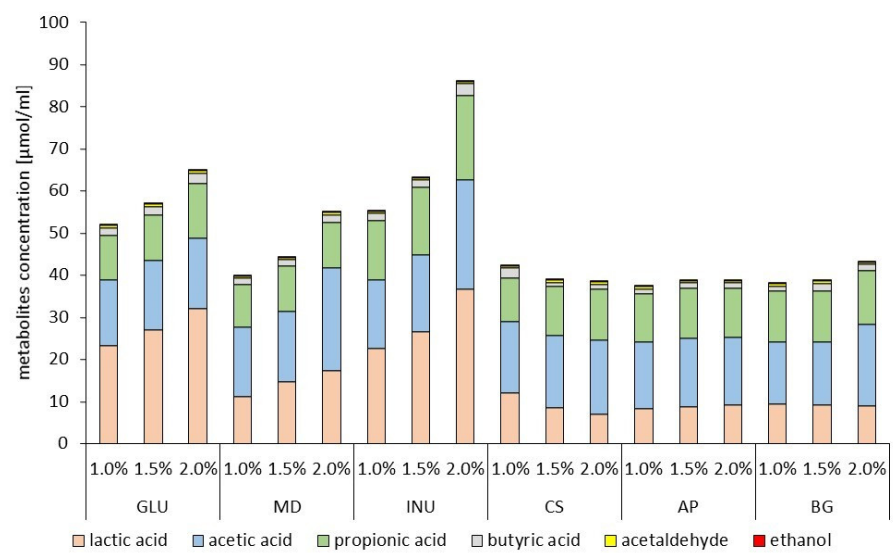

(g)

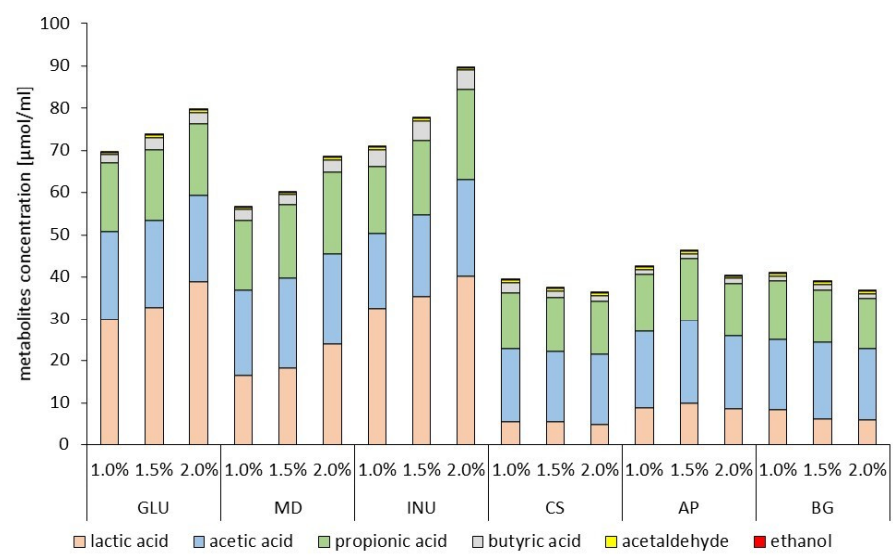

(i)

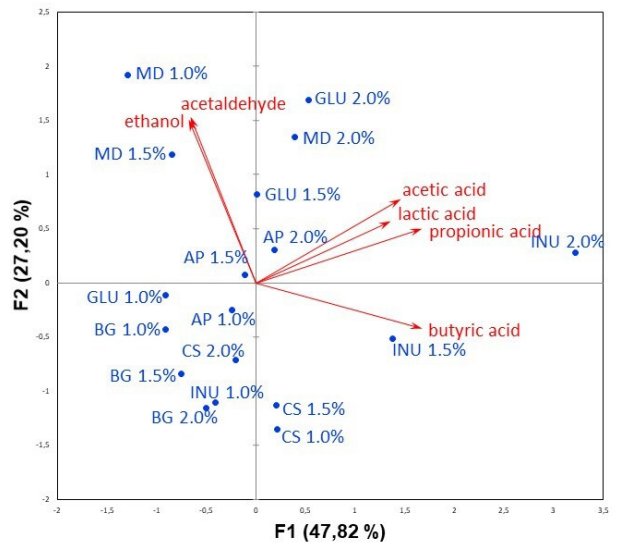

(f)

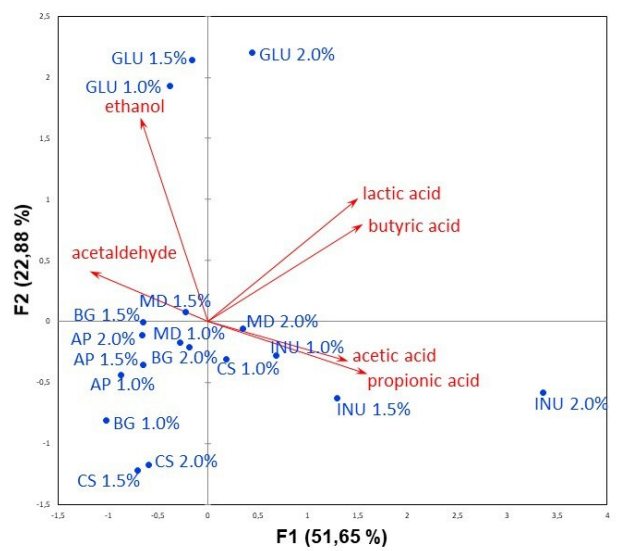

(h)

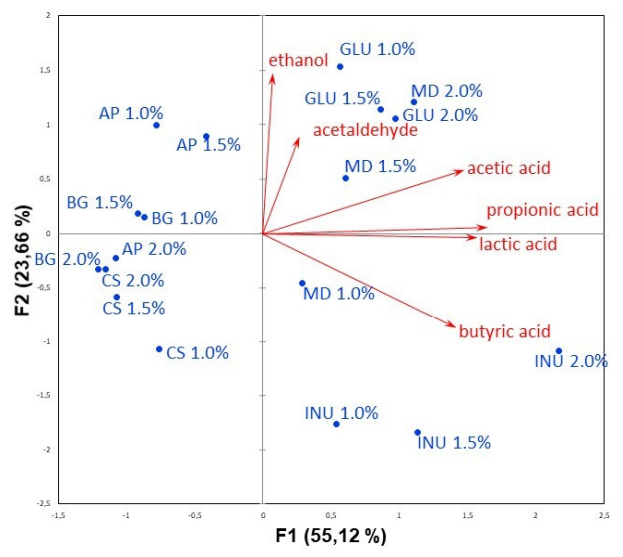

(j)

Figure 1. Metabolites concentration produced by probiotic strains, namely, (a) Lb. rhamnosus ŁOCK 1087, (c) Lb. paracasei ŁOCK 1091, (e) Lb. reuteri ŁOCK 1092, (g) Lb. plantarum ŁOCK 0860, and (i) $L b$. pentosus ŁOCK 1094 in dependence on the used prebiotic (MD-maltodextrin, INU-inulin, CS-corn starch, AP-apple pectin, BG- $\beta$-glucan) or glucose (GLU) comparatively as a carbon source in the cultivation medium. Moreover, the correlations between used carbohydrates, as well as their concentrations, and the synthesized amount of metabolites, were presented as the PCA biplots, namely, plots $(\mathbf{b}, \mathbf{d}, \mathbf{f}, \mathbf{h}, \mathbf{j})$ for above-mentioned strains, respectively. 


\subsection{Enzymatic Identification of Optically Active Forms of Lactic Acid}

As a result of the analysis, both lactic acid isomers- $\mathrm{D}(-)$ and $\mathrm{L}(+)$ - were detected when the probiotic strains were grown in the presence of all tested prebiotics, and when glucose was used as the carbon source (Table 3).

Table 3. Influence of prebiotics on the synthesis of optically active forms of lactic acid by Lactobacillus spp. strains.

\begin{tabular}{|c|c|c|c|c|c|c|c|}
\hline \multirow{3}{*}{ 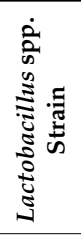 } & \multirow{3}{*}{ 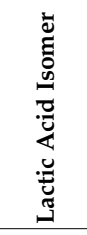 } & \multicolumn{6}{|c|}{ Carbon Source $^{1}$} \\
\hline & & GLU & MD & INU & CS & AP & BG \\
\hline & & \multicolumn{6}{|c|}{ Concentration $[g / 1]^{2}$} \\
\hline \multirow{3}{*}{ 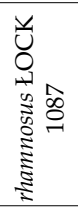 } & $\mathrm{D}(-)$ & $0.942 \pm 0.027 \mathrm{~d}, \mathrm{e}$ & $0.119 \pm 0.008^{\mathrm{a}, \mathrm{b}}$ & $\underset{\mathrm{a}, \mathrm{b}, \mathrm{c}, \mathrm{d}}{0.075}$ & $0.087 \pm 0.004^{a}$ & $0.166 \pm 0.048^{\mathrm{a}, \mathrm{b}}$ & $0.088 \pm 0.014^{\mathrm{a}}$ \\
\hline & $\mathrm{L}(+)$ & $4.570 \pm 1.106^{\mathrm{g}}$ & $\begin{array}{c}0.407 \pm 0.003 \\
\mathrm{a}, \mathrm{b}, \mathrm{c}\end{array}$ & $6.634 \pm 0.996^{h, i}$ & $0.106 \pm 0.003^{\mathrm{a}, \mathrm{b}}$ & $0.083 \pm 0.007^{\mathrm{a}}$ & $0.105 \pm 0.009 \mathrm{a}, \mathrm{b}$ \\
\hline & Total & $5.512 \pm 1.079^{\text {B }}$ & $0.527 \pm 0.011^{\mathrm{A}}$ & $6.634 \pm 0.921^{\text {В }}$ & $0.193 \pm 0.001 \mathrm{~A}$ & $0.249 \pm 0.019^{\mathrm{A}}$ & $0.193 \pm 0.022 \mathrm{~A}$ \\
\hline \multirow{3}{*}{ 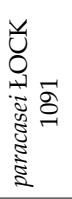 } & $\mathrm{D}(-)$ & $4.511 \pm 0.412 \mathrm{~g}$ & $0.112 \pm 0.015^{\mathrm{a}, \mathrm{b}}$ & $2.200 \pm 0.301^{\mathrm{f}}$ & $0.023 \pm 0.002^{\mathrm{a}}$ & $0.094 \pm 0.003^{a}$ & $0.049 \pm 0.006^{\mathrm{a}}$ \\
\hline & $\mathrm{L}(+)$ & $2.424 \pm 0.110^{\mathrm{f}}$ & $\begin{array}{c}0.547 \pm 0.019 \\
\text { a,b,c, d,e }\end{array}$ & $5.701 \pm 0.105^{\mathrm{h}}$ & $0.032 \pm 0.002^{\mathrm{a}}$ & $0.169 \pm 0.049^{a, b}$ & $0.057 \pm 0.005^{\mathrm{a}}$ \\
\hline & Total & $6.935 \pm 0.522^{C}$ & $0.659 \pm 0.004^{\mathrm{B}}$ & $7.901 \pm 0.196^{\mathrm{D}}$ & $0.056 \pm 0.005^{\mathrm{A}}$ & $0.263 \pm 0.046^{\mathrm{A}, \mathrm{B}}$ & $0.106 \pm 0.012^{\mathrm{A}}$ \\
\hline \multirow{3}{*}{ 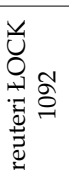 } & $\mathrm{D}(-)$ & $0.950 \pm 0.029 \mathrm{e}$ & $0.091 \pm 0.007^{\mathrm{a}}$ & $0.517 \pm 0.111$ & $0.025 \pm 0.002^{\mathrm{a}}$ & $0.026 \pm 0.001^{\mathrm{a}}$ & $0.017 \pm 0.001^{\mathrm{a}}$ \\
\hline & $\mathrm{L}(+)$ & $4.698 \pm 0.381 \mathrm{~g}$ & $\begin{array}{l}0.472 \pm 0.001 \\
\mathrm{a}, \mathrm{b}, \mathrm{c}, \mathrm{d}, \mathrm{e}\end{array}$ & $7.282 \pm 0.206^{j}$ & $0.076 \pm 0.009^{a}$ & $0.071 \pm 0.009^{\mathrm{a}}$ & $0.078 \pm 0.005^{\mathrm{a}}$ \\
\hline & Total & $5.648 \pm 0.411^{\mathrm{C}}$ & $0.563 \pm 0.007^{\text {B }}$ & $7.799 \pm 0.317^{\mathrm{D}}$ & $0.101 \pm 0.011^{\mathrm{A}}$ & $0.097 \pm 0.009^{\mathrm{A}}$ & $0.095 \pm 0.005^{\mathrm{A}}$ \\
\hline \multirow{3}{*}{ 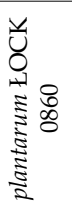 } & $\mathrm{D}(-)$ & $1.003 \pm 0.014^{\mathrm{e}}$ & $0.067 \pm 0.002^{\mathrm{a}}$ & $\begin{array}{c}0.501 \pm 0.007 \\
\mathrm{a}, \mathrm{b}, \mathrm{c}, \mathrm{d}, \mathrm{e}\end{array}$ & $0.008 \pm 0.001^{\mathrm{a}}$ & $0.034 \pm 0.005^{\mathrm{a}}$ & $0.020 \pm 0.003^{a}$ \\
\hline & $\mathrm{L}(+)$ & $6.285 \pm 0.089^{\mathrm{i}}$ & $\begin{array}{c}0.487 \pm 0.013 \\
\mathrm{a}, \mathrm{b}, \mathrm{c}, \mathrm{d}, \mathrm{e}\end{array}$ & $7.044 \pm 0.089^{j}$ & $0.059 \pm 0.002^{\mathrm{a}}$ & $0.095 \pm 0.002^{\mathrm{a}}$ & $0.085 \pm 0.011^{\mathrm{a}}$ \\
\hline & Total & $7.287 \pm 0.076^{\mathrm{C}}$ & $0.554 \pm 0.011^{\mathrm{B}}$ & $7.546 \pm 0.082^{\mathrm{D}}$ & $0.068 \pm 0.009 \mathrm{~A}$ & $0.129 \pm 0.017^{\mathrm{A}}$ & $0.104 \pm 0.008^{\mathrm{A}}$ \\
\hline \multirow{3}{*}{ 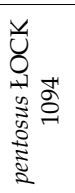 } & $\mathrm{D}(-)$ & $\begin{array}{c}0.798 \pm 0.085 \\
c, d, e\end{array}$ & $0.051 \pm 0.040^{\mathrm{a}}$ & $\begin{array}{c}0.284 \pm 0.052 \\
\mathrm{a}, \mathrm{b}, \mathrm{c}\end{array}$ & $0.046 \pm 0.005^{\mathrm{a}}$ & $0.085 \pm 0.004^{\mathrm{a}}$ & $0.027 \pm 0.002^{\mathrm{a}}$ \\
\hline & $\mathrm{L}(+)$ & $4.237 \pm 0.183 \mathrm{~g}$ & $\begin{array}{c}0.642 \pm 0.084 \\
\mathrm{~b}, \mathrm{c}, \mathrm{d}, \mathrm{e}\end{array}$ & $7.248 \pm 0.304 \mathrm{j}$ & $0.074 \pm 0.011^{\mathrm{a}}$ & $0.061 \pm 0.005^{\mathrm{a}}$ & $0.054 \pm 0.004^{\mathrm{a}}$ \\
\hline & Total & $5.035 \pm 0.103^{C}$ & $0.692 \pm 0.44^{\text {B }}$ & $7.531 \pm 0.252^{\mathrm{D}}$ & $0.120 \pm 0.016^{A}$ & $0.146 \pm 0.001^{\mathrm{A}}$ & $0.081 \pm 0.008^{A}$ \\
\hline
\end{tabular}

The probiotic strains cultivated in the presence of corn starch, apple pectin, $\beta$-glucan, and maltodextrin synthesized significantly less total lactic acid than when glucose was used as the carbohydrate (Table 3). Moreover, no vital statistical differences in the concentrations of $\mathrm{D}(-)$ and $\mathrm{L}(+)$ isomers of this organic acid were observed when these prebiotics were used.

Significantly higher total concentrations of lactic acid produced by the analyzed strains were observed when inulin was fermented than in the presence of glucose. Furthermore, inulin had a beneficial impact on the ratio of optically active forms of lactic acid produced by the probiotic strains; the $\mathrm{L}(+)$ isomer was predominantly produced. The percentage share of $\mathrm{L}(+)$ form of lactic acid produced by most of the tested strains in the process of inulin degradation exceeded $93 \%$, with the exception of $L b$. paracasei ŁOCK 1091 (72.16\%). An analogous dependency was noted when glucose was used as the carbon source for the strains, with the exception of Lb. paracasei ŁOCK 1091; however, 
the L-lactic acid percentages in the total amount of the metabolite were lower, varying between $35 \%$ and $86 \%$.

\subsection{Enzymatic Profile of Probiotic Lactobacillus spp. in the Presence of Prebiotics}

Based on the API ${ }^{\circledR}$ ZYM assay, it was observed that each strain exhibited activity of leucine arylamidase, acid phosphatase, naphthol-AS-BI-phosphohydrolase, $\beta$-galactosidase, as well as $\alpha$ - and $\beta$-glucosidase independent of the carbon source used for cultivation. However, the selected strains cultivated in the presence of glucose or prebiotics did not show lipase, trypsin, chymotrypsin, $\beta$-glucuronidase, $\alpha$-mannosidase, or $\alpha$-fucosidase activity (except for Lb. rhamnosus ŁOCK 1087).

On the contrary, differences in the enzymatic profile of the selected probiotic strains in relation to the prebiotic substance used as the carbohydrate during cultivation were observed in terms of alkaline phosphatase and cystine arylamidase. The enzymatic profiles of Lb. rhamnosus ŁOCK 1087 and $L b$. pentosus ŁOCK 1094 did not include alkaline phosphate when apple pectin was used as the carbon source. This enzyme activity was observed for Lb. paracasei ŁOCK 1091, Lb. reuteri ŁOCK 1092, and $L b$ plantarum ŁOCK 0860 when inulin, apple pectin, maltodextrin, or corn starch were used as carbohydrates in the cultivation process. However, cystine arylamidase activity was observed for $L b$. rhamnosus ŁOCK 1087, Lb. paracasei ŁOCK 1091, Lb. reuteri ŁOCK1092, and Lb. pentosus ŁOCK 1094 when maltodextrin, inulin, or corn starch were used as the carbon source. Moreover, the activity of n-acetyl- $\beta$-glucosaminidase, which was carbon source-dependent was not observed only when inulin and glucose were fermented.

The lowest enzymatic activity was observed for $L b$. plantarum ŁOCK 0860, which was the only studied strain that did not present cystine arylamidase and $\alpha$-galactosidase activity. Moreover, esterase, lipase esterase, and valine arylamidase activity was carbon source-dependent, where in the presence of apple pectin, $\beta$-glucan, and glucose, $L b$. plantarum ŁOCK 0860 mostly did not exhibit those enzymes' activity.

The enzymatic activity results are presented in Figure 2.

\subsection{The Influence of the Prebiotics on the Antagonistic Activity of Lactobacillus spp. Strains towards} Pathogenic Bacteria

The antimicrobial potential of a mixture of the Lactobacillus spp. strains, including Lb. rhamnosus ŁOCK 1087, Lb. paracasei ŁOCK 1091, Lb. reuteri ŁOCK 1092, Lb. plantarum ŁOCK 0860, and Lb. pentosus ŁOCK 1094 towards pathogens varied (Figure 3). Based on the results obtained, it was noted that the ability to reduce the number of pathogenic bacteria was dependent on the prebiotic used as a carbon source in co-cultures, as well as the type of pathogens.

The strongest antagonistic activity was observed when a co-culture with each pathogen was conducted in the presence of $2 \%(w / v)$ inulin, which resulted in a total reduction of the Salmonella spp. strains, being undetectable after $24 \mathrm{~h}$ of incubation (Figure $3 \mathrm{~b}-\mathrm{d}$ ). The number of L. monocytogenes, however, was reduced from 7.29 logarithmic units to 2.39 , which amounts to a reduction of almost $70 \%$ of the bacterial count (Figure 3a).

On the other hand, corn starch used as the carbon source for the probiotic mixture culture resulted in a decline of these strains' ability to reduce the number of all analyzed pathogenic bacteria in comparison to the effect observed when glucose was metabolized. An analogous dependency was observed in the probiotic mixture co-culture with L. monocytogenes in the presence of maltodextrin, as well as towards $S$. Choleraesuis when the apple pectin and $\beta$-glucan were used as the carbon sources (Figure 3a,d). 


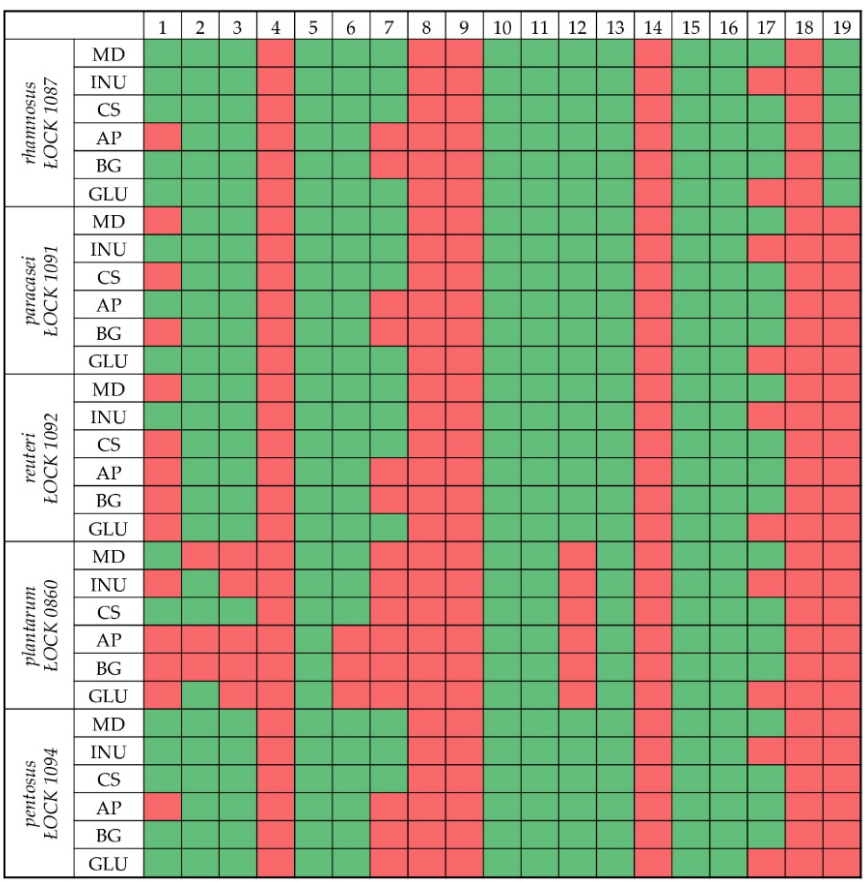

Positive reaction

Lack of enzyme activity

Figure 2. Heatmap presenting the Lactobacillus spp. strains enzymatic profile in relation to carbohydrates used in the culture: MD-maltodextrin, INU-inulin, CS-corn starch, AP-apple pectin, BG- $\beta$-glucan, and GLU-glucose. The tested enzymes were enumerated as follows: 1-alkaline phosphatase, 2-esterase (C4), 3-lipase esterase (C8), 4-lipase (C14), 5-leucine arylamidase, 6-valine arylamidase, 7-cystine arylamidase, 8-trypsin, 9-chymotrypsin, 10-acid phosphatase, 11-naphthol-AS-BI-phosphohydrolase, 12 - $\alpha$-galactosidase, 13- $\beta$-galactosidase, $14-\beta$-glucuronidase, 15 - $\alpha$-glucosidase, $16-\beta$-glucosidase, 17-n-acetyl- $\beta$-glucosaminidase, $18-\alpha$-mannosidase, 19 - $\alpha$-fucosidase.

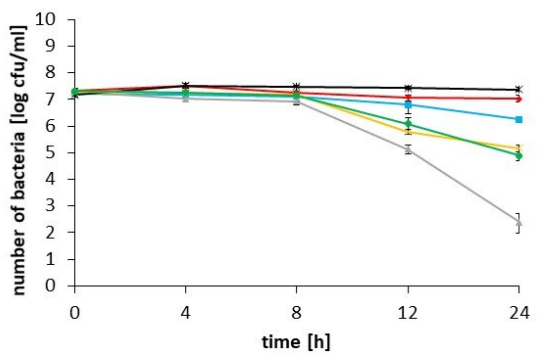

(a)

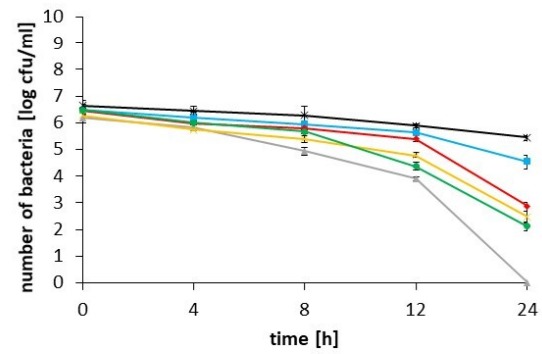

(c)

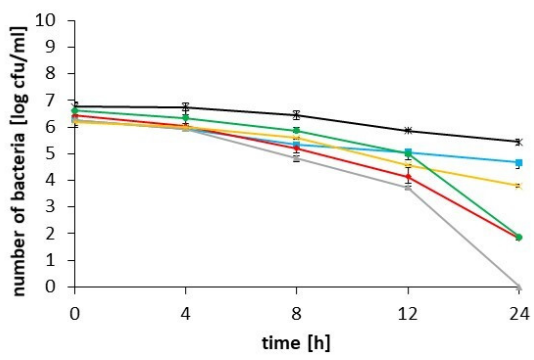

(b)

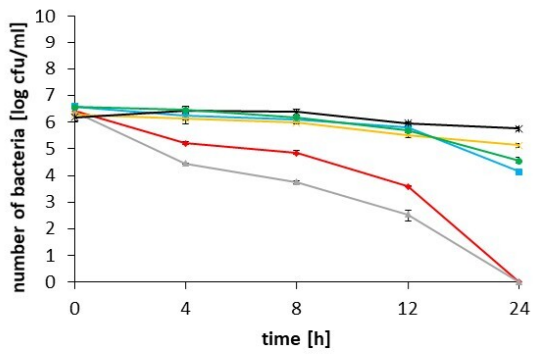

(d)

$\rightarrow-\mathrm{GLU} \rightarrow \mathrm{MD} \rightarrow-\mathrm{INU} \sim \mathrm{AP} \rightarrow \mathrm{CS} \rightarrow \mathrm{BG}$

Figure 3. Antagonistic activity of a mixture of the probiotic strains, namely, Lb. rhamnosus ŁOCK 1087, Lb. paracasei ŁOCK 1091, Lb. reuteri ŁOCK 1092, Lb. plantarum ŁOCK 0860, and Lb. pentosus ŁOCK 1094 on the pathogenic bacteria: (a) L. monocytogenes, (b) S. Enteritidis, (c) S. Typhimurium, and (d) S. Choleraesuis. The co-cultures were conducted in the presence of each carbohydrate (MD-maltodextrtin, INU-inulin, AP-apple pectin, CS-corn starch, BG- $\beta$-glucan, or GLU-glucose). 
Furthermore, the most susceptible pathogens to antagonistic activity were the analyzed Salmonella spp. strains, with the exception of the co-cultures cultivated in the presence of apple pectin and $\beta$-glucan, for which antagonism towards $S$. Choleraesuis was weaker than against $L$. monocytogenes.

\section{Discussion}

Despite glucose being commonly used as the carbon source for the cultivation of Lactic Acid Bacteria (LAB), their ability to degrade various carbohydrates is well-established and known to be strain-dependent, which was also observed in our studies [22]. Based on the results, it was concluded that the analyzed strains were able to utilize all the tested prebiotics, though they varied in relation to the type and concentration of the carbohydrates. Contrary to data presented in this study, Watson et al. (2012) showed that the growth of Lactobacillus spp. strains in the presence of maltodextrin and inulin was poor compared to the effect caused by glucose [23]. A similar dependency was observed by Iraporda et al. (2019) in terms of the inulin effect [24]. Also, McLaughlin et al. (2015) noted that maltodextrin, $\beta$-glucan, or corn fiber used as the carbon source for the cultivation of Lactobacillus spp. strains resulted in no growth or weaker growth than when glucose was used as the carbohydrate, which was opposite to our data [25]. Moreover, the researchers observed that inulin supported the growth ability of one of the ten tested Lactobacillus spp. strains to a comparable extent as glucose, which also indicates the strain-dependent character of these bacteria's abilities to utilize carbohydrates [25]. Similar results were observed by Nazzaro et al. (2012), whose data showed no significant differences in the growth performance of $L b$. acidophilus DSM 20079 when inulin, pectin, or glucose was used as the carbohydrates for the bacteria cultivation [12]. On the contrary, the results described by Kunová et al. (2011) indicate that inulin stimulated the growth of Lactobacillus spp. to the greatest extent among five other prebiotics [26]. The data was in line with ours for $L b$. rhamnosus ŁOCK 1087, Lb. reuteri ŁOCK 1092, and Lb. plantarum ŁOCK 0860 cultivated in the presence of $2 \%(w / v)$ inulin. Furthermore, Önal Darilmaz et al. (2019) showed increased growth of tested Lactobacillus spp. strains in the presence of 5\% $(w / v)$ inulin compared to cultures conducted in unmodified MRS medium with 2\% (w/v) glucose [27]. The results described in this article show that the selected Lactobacillus spp. strains have a greater ability to adapt and to degrade a wider spectrum of carbohydrates than the ones analyzed by previously mentioned researchers. Nevertheless, for the purpose of a synbiotic elaboration purposes, the inulin in the concentration of $2 \%(w / v)$ was the most beneficial for the selected strains.

Based on the metabolic profile, LAB are divided into two categories, namely homo- and heterofermentative bacteria, which degrade carbohydrates mainly into lactic acid (around $85 \%$ of the end products) or acetic acid and ethanol along with lactic acid (no less than $50 \%$ of all metabolites), respectively [28]. The results described in this article indicate the heterofermentative character of these strains, which produced lactic, acetic, and propionic acids in significantly higher concentrations than butyrate, acetaldehyde, and ethanol. According to data presented, only inulin proved to enhance the synthesis of lactate and SCFAs, which could prevent the colonization of the GIT by pathogens and improve the host's overall health $[29,30]$. To this day, not many studies have been published, considering the impact of the prebiotics analyzed in this article-apart from inulin-on the metabolites produced by Lactobacillus spp. Nevertheless, contrary to the data obtained, Sharma and Kanwar (2018) observed a significantly lower concentration of lactic acid produced in the process of inulin fermentation than when glucose was used [31]. However, the researchers noted that inulin promoted the production of acetic, propionic, and butyric acids, which was in line with our results and the data described by de Souza Oliveira et al. (2012) [31,32]. Moreover, inulin reduced the amount of ethanol and acetaldehyde produced, which was considered beneficial since the acetaldehyde could be produced from ethanol in the process of oxidation and itself poses carcinogenic potential and could cause chromosomal mutations [33]. These results support the idea of developing a synbiotic combining the selected probiotic strains and $2 \%(w / v)$ inulin, since the main mechanism of prebiotics' beneficial impact on health is through the enhanced synthesis of SCFAs. 
Typically, the racemic mixture of both lactic acid isomers- $\mathrm{D}(-)$ and $\mathrm{L}(+)$ - is created as a result of carbohydrate fermentation; however, the ratio of the optical forms can differ depending on the carbon source and the LAB strain $[34,35]$, which was in line with the results of this study. The accumulation of D-lactic acid can be harmful to the host, since it could lead to a D-lactic acidosis resulting in confusion, behavioral changes, ataxia, or even coma $[34,36]$. Moreover, D-lactate isomer could diminish the availability of L-lactic acid for neurons, for which it poses as the energy source [37], which is why the enhancement of L-lactic acid synthesis at the expense of D-lactic acid concentration caused by inulin can be considered beneficial. The data presented in this article are similar to the results obtained by Goderska et al. (2008) [38], though these researchers observed lower proportions of L-lactic acid.

Prebiotic components degradation end products, especially lactic acid and SCFAs, are known to promote the antagonistic activity of probiotic strains [39,40]. We observed that inulin used as the carbohydrate in the probiotics culture was associated with the strongest enhancement in organic acids production, as well as with the greatest antimicrobial properties, which was also concluded by Likotrafiti et al. (2015) [41]. Kanjan and Hongpattarakere (2017) observed a total reduction of viable $S$. Typhimurium SA2093 cells in the presence of both inulin and the probiotic $L b$. paracasei I321, which agrees with our data [39]. In addition to that, Chaiyasut et al. (2017) also observed a significant reduction in Salmonella spp. count in the presence of inulin-degrading Lactobacillus spp. and the prebiotic compound [42]. Moreover, the results show that inulin also significantly stimulates the antagonistic activity of the probiotic mixture towards L. monocytogenes, which was the opposite of what was described by Likotrafiti et al. (2015) in their study [41]. Our results indicate that the application of the combination of the selected strains with inulin could improve the antagonistic activity towards pathogenic bacteria, inhibiting their growth and therefore preventing infectious diseases.

Furthermore, it was noted that the carbohydrates analyzed in this study did not significantly impact the enzymatic profile of the probiotic Lactobacillus spp. strains, although changes were noted. Independently of the carbon source, common activities of enzymes were observed for Lactobacillus spp., such as $\beta$-galactosidase being responsible for lactose hydrolysis, $\beta$-glucosidase impacting the ability of Lactobacillus spp. to endure higher temperatures and breaking glycosidic bonds, acid phosphatase helping to obtain energy from phosphates, or naphthol-AS-BI-phosphohydrolase being responsible for alkaloids, nucleotides, and proteins dephosphorylation [43-47]. In addition to that, all of the strains lack the activity of potentially harmful enzymes, like $\beta$-glucuronidase-which is associated with toxic, mutagenic, and carcinogenic potential-as well as chymotrypsin, which is associated with GIT diseases $[47,48]$. Similar enzymatic profiles of Lactobacillus spp. strains have been described by Pisano et al. (2014), O'Donnell et al. (2015), and Aziz et al. (2019) [48-50]. On the other hand, it was noted that n-acetyl- $\beta$-glucosaminidase, alkaline phosphatase, and cystine arylamidase activity were carbohydrate-dependent. Maltodextrin, corn starch, apple pectin, and $\beta$-glucan promoted $n$-acetyl- $\beta$-glucosaminidase activity in Lactobacillus spp. strains, which indicates an unfavorable change in metabolic profile, because the enzyme could cause intestinal diseases [48]. These prebiotics used as the carbon source also resulted in a lack of alkaline phosphatase activity, which constitutes an adverse effect in terms of probiotic properties of the strains, since this enzyme could improve immunomodulation and inhibit inflammatory responses in the GIT [51]. We observed that the enzymatic profiles of the selected Lactobacillus spp. strains only remained unchanged in the presence of inulin, compared to that exhibited by these strains when glucose was fermented. The others of the analyzed prebiotic carbohydrates induced potentially negative enzymatic activity, which could detrimentally affect health.

In summary, the replacement of glucose with inulin resulted in beneficial metabolic changes and enhanced some of the probiotic features of the Lactobacillus spp. strains, which was opposite to the effect caused by the rest of the analyzed prebiotics.

\section{Conclusions}

Prebiotics are thought to be selectively utilized by beneficial microorganisms and to confer a positive effect on host health. Using a combination of pro- and prebiotics, in the form of a synbiotic, 
should result in a more favorable effect on the host in comparison to using these components individually. Furthermore, the growth and activity of the probiotic strains should be enhanced by the prebiotic component.

Based on the results obtained, we concluded that only inulin is suitable for use as a prebiotic for the selected Lactobacillus spp. strains, since not only was their growth promoted, but the metabolism was also more beneficial and the antagonistic activity against pathogens intensified. Moreover, the usage of inulin as a carbohydrate in the culture medium did not have a negative impact on the enzymatic profile, a finding which was observed in the presence of the rest of prebiotics. As a result of that, a synbiotic combination of $2 \%(w / v)$ inulin with the probiotic strains could help prevent gastrointestinal infections and maintain proper $\mathrm{pH}$ levels in the GIT, leading to balanced microbiota. The positive changes in the amount of lactic acid and SCFAs produced as a result of inulin fermentation may have a beneficial impact on the host's GIT health and functionality, though further in vivo studies are necessary.

Author Contributions: Conceptualization, K.Ś.; methodology, K.Ś. and A.C.-W.; formal analysis, A.C.-W.; investigation, A.C.-W. and K.Ś.; resources, K.Ś.; data curation, A.C.-W..; writing-A.C.-W. and K.Ś.; writing-review and editing, A.C.-W.; visualization, A.C.-W.; supervision, K.S.; project administration, K.Ś.; funding acquisition, K.Ś. All authors have read and agreed to the published version of the manuscript.

Funding: This research was funded by the National Centre for Research and Development, grant number PBS3/A8/32/2015.

Acknowledgments: We would like to thank the National Centre for Research and Development for the financial support of the research and publication of this paper as part of the project PBS3/A8/32/2015 realized within the framework of the Program of Applied Studies.

Conflicts of Interest: The authors declare no conflict of interest.

\section{References}

1. FAO; WHO. Guidelines for the Evaluation of Probiotics in Food; Food Agriculture Organization: Rome, Italy; World Health Organation: Geneva, Switzerland, 2002.

2. Gibson, G.R.; Roberfroid, M.B. Dietary Modulation of the Human Colonic Microbiota: Introducing the Concept of Prebiotics. J. Nutr. 1995, 125, 1401-1412. [CrossRef] [PubMed]

3. Gibson, G.R.; Hutkins, R.; Sanders, M.E.; Prescott, S.L.; Reimer, R.A.; Salminen, S.J.; Scott, K.; Stanton, C.; Swanson, K.S.; Cani, P.D.; et al. Expert consensus document: The International Scientific Association for Probiotics and Prebiotics (ISAPP) consensus statement on the definition and scope of prebiotics. Nat. Rev. Gastroenterol. Hepatol. 2017, 14, 491-502. [CrossRef] [PubMed]

4. De Paulo Farias, D.; De Araújo, F.F.; Neri-Numa, I.A.; Pastore, G.M. Prebiotics: Trends in food, health and technological applications. Trends Food Sci. Technol. 2019, 93, 23-25. [CrossRef]

5. Gomaa, E.Z. Effect of prebiotic substances on growth, fatty acid profile and probiotic characteristics of Lactobacillus brevis NM101-1. Microbiology (Russian Federation) 2017, 86, 618-628. [CrossRef]

6. Pabari, K.; Pithva, S.; Kothari, C.; Purama, R.K.; Kondepudi, K.K.; Vyas, B.R.M.; Kothari, R.; Ambalam, P. Evaluation of Probiotic Properties and Prebiotic Utilization Potential of Weissella paramesenteroides Isolated From Fruits. Probiotics Antimicrob. Proteins 2020. [CrossRef] [PubMed]

7. Pandey, A.K.; Kumar, P.; Saxena, M.J. Feed Additives in Animal Health. In Nutraceuticals in Veterinary Medicine; Gupta, R.C., Srivastava, A., Lall, R., Eds.; Springer: Cham, Switzerland, 2019; pp. 345-362.

8. Sharma, S.; Bano, A.; Gupta, A.; Bajpai, P.; Lohani, M.; Pathak, N. Pre- and Probiotics: Using Functional Foods in the Fight Against Microbial Resistance to Antibiotics. In Antibacterial Drug Discovery to Combat MDR; Ahmad, I., Ahmad, S., Rumbaugh, K., Eds.; Springer: Singapore, 2019; pp. 397-425.

9. Rawi, M.H.; Zaman, S.A.; Pa'ee, K.F.; Leong, S.S.; Sarbini, S.R. Prebiotics metabolism by gut-isolated probiotics. J. Food Sci. Technol. 2020. [CrossRef]

10. Davani-Davari, D.; Negahdaripour, M.; Karimzadeh, I.; Seifan, M.; Mohkam, M.; Masoumi, S.J;; Berenjian, A.; Ghasemi, Y. Prebiotics: Definition, types, sources, mechanisms, and clinical applications. Foods 2019, 8, 92. [CrossRef]

11. Slavin, J. Fiber and prebiotics: Mechanisms and health benefits. Nutrients 2013, 5, 1417-1435. [CrossRef] 
12. Nazzaro, F.; Fratianni, F.; Nicolaus, B.; Poli, A.; Orlando, P. The prebiotic source influences the growth, biochemical features and survival under simulated gastrointestinal conditions of the probiotic Lactobacillus acidophilus. Anaerobe 2012, 18, 280-285. [CrossRef]

13. Anadón, A.; Ares, I.; Martínez-Larrañaga, M.R.; Martínez, M.A. Prebiotics and Probiotics in Feed and Animal Health. In Nutraceuticals in Veterinary Medicine; Gupta, R.C., Srivastava, A., Lall, R., Eds.; Springer: Cham, Switzerland, 2019.

14. Dhewa, T.; Pant, S.; Mishra, V. Development of freeze dried synbiotic formulation using a probiotic strain of Lactobacillus plantarum. J. Food Sci. Technol. 2014, 51, 83-89. [CrossRef]

15. Yoo, J.Y.; Kim, S.S. Probiotics and Prebiotics: Present Status and Future Perspectives on Metabolic Disorders. Nutrients 2016, 8, 173. [CrossRef] [PubMed]

16. Institute of Fermentation Technology and Microbiology. Pure Cultures Collection (ŁOCK 105). Available online: http://mikrobiologia.p.lodz.pl/kolekcja-lock/ (accessed on 20 April 2020).

17. Śliżewska, K.; Chlebicz, A. Lactic Bacterial Strain of Lactobacillus pentosus. PL Patent 233261 B1, 30 September 2019.

18. Śliżewska, K.; Chlebicz, A. Lactic Bacterial Strain of Lactobacillus reuteri. PL Patent 233263 B1, 30 September 2019.

19. Śliżewska, K.; Chlebicz, A. Lactic Bacterial Strain of Lactobacillus rhamnosus. PL Patent 233582 B1, 29 November 2019.

20. Śliżewska, K.; Chlebicz, A. Lactic Bacterial Strain of Lactobacillus paracasei. PL Patent 233262 B1, 30 September 2019.

21. Śliżewska, K.; Motyl, I.; Libudzisz, Z.; Otlewska, A.; Burchardt, H.; Klecha, J.; Henzler, J. Lactobacillus plantarum lactic bacteria strain. PL Patent 221959 B1, 30 June 2016.

22. Hayek, S.A.; Ibrahim, S.A. Current Limitations and Challenges with Lactic Acid Bacteria: A Review. Food Nutr. Sci. 2013, 4, 73-87. [CrossRef]

23. Watson, D.; O'Connell Motherway, M.; Schoterman, M.H.C.; van Neerven, R.J.J.; Nauta, A.; Van Sinderen, D. Selective carbohydrate utilization by lactobacilli and bifidobacteria. J. Appl. Microbiol. 2013, 114, 1132-1146. [CrossRef] [PubMed]

24. Iraporda, C.; Rubel, I.A.; Manrique, G.D.; Abraham, A.G. Influence of inulin rich carbohydrates from Jerusalem artichoke (Helianthus tuberosus L.) tubers on probiotic properties of Lactobacillus strains. LWT Food Sci. Technol. 2019, 101, 738-746. [CrossRef]

25. McLaughlin, H.P.; Motherway, M.O.C.; Lakshminarayanan, B.; Stanton, C.; Paul Ross, R.; Brulc, J.; Menon, R.; O'Toole, P.W.; van Sinderen, D. Carbohydrate catabolic diversity of bifidobacteria and lactobacilli of human origin. Int. J. Food Microbiol. 2015, 203, 109-121. [CrossRef]

26. Kunová, G.; Rada, V.; Lisová, I.; Ročková, Š.; Vlková, E. In vitro fermentability of prebiotic oligosaccharides by lactobacilli. Czech J. Food Sci. 2018, 29, 49-54. [CrossRef]

27. Önal Darilmaz, D.; Sönmez, Ş.; Beyatli, Y. The effects of inulin as a prebiotic supplement and the synbiotic interactions of probiotics to improve oxalate degrading activity. Int. J. Food Sci. Technol. 2019, 54, 12-131. [CrossRef]

28. König, H.; Fröhlich, J. Lactic acid bacteria. In Biology of Microorganisms on Grapes, in Must and in Wine; Springer: Berlin/Heidelberg, Germany, 2017; pp. 3-41. ISBN 9783319600215.

29. Chen, C.C.; Lai, C.C.; Huang, H.L.; Huang, W.Y.; Toh, H.S.; Weng, T.C.; Chuang, Y.C.; Lu, Y.C.; Tang, H.J. Antimicrobial activity of Lactobacillus species against carbapenem-resistant Enterobact. Front. Microbiol. 2019, 10, 789. [CrossRef]

30. Tingirikari, J.M.R. In-Vitro Prebiotic Analysis of Microbiota Accessible Pectic Polysaccharides. Curr. Microbiol. 2019, 76, 1452-1460. [CrossRef]

31. Sharma, S.; Kanwar, S.S. Effect of prebiotics on growth behavior of Lactobacillus plantarum and their impact on adherence of strict anaerobic pathogens to intestinal cell lines. J. Food Saf. 2018, 38, e12384. [CrossRef]

32. De Souza Oliveira, R.P.; Perego, P.; de Oliveira, M.N.; Converti, A. Effect of inulin on the growth and metabolism of a probiotic strain of Lactobacillus rhamnosus in co-culture with Streptococcus thermophilus. LWT Food Sci. Technol. 2012, 47, 358-363. [CrossRef]

33. Tagaino, R.; Washio, J.; Abiko, Y.; Tanda, N.; Sasaki, K.; Takahashi, N. Metabolic property of acetaldehyde production from ethanol and glucose by oral Streptococcus and Neisseria. Sci. Rep. 2019, 9, 10446. [CrossRef] [PubMed] 
34. Cizeikiene, D.; Juodeikiene, G.; Damasius, J. Use of wheat straw biomass in production of L-lactic acid applying biocatalysis and combined lactic acid bacteria strains belonging to the genus Lactobacillus. Biocatal. Agric. Biotechnol. 2018, 15, 185-191. [CrossRef]

35. Trontel, A.; Batušić, A.; Gusić, I.; Slavica, A.; Šantek, B.; Novak, S. Production of D- and L-lactic acid by mono- and mixed cultures of Lactobacillus sp. Food Technol. Biotechnol. 2011, 49, 75-82.

36. Mack, D.R. D(-)-lactic acid-producing probiotics, D(-)-lactic acidosis and infants. Can. J. Gastroenterol. 2004, 18, 75-82. [CrossRef]

37. Mayeur, C.; Gratadoux, J.-J.; Bridonneau, C.; Chegdani, F.; Larroque, B.; Kapel, N.; Corcos, O.; Thomas, M.; Joly, F. Faecal D/L Lactate Ratio Is a Metabolic Signature of Microbiota Imbalance in Patients with Short Bowel Syndrome. PLoS ONE 2013, 8, e54335. [CrossRef]

38. Goderska, K.; Nowak, J.; Czarnecki,Z. Comparison of the growth of Lactobacillus acidophilus and Bifidobacterium bifidum species in media supplemented with selected saccharides including prebiotics. Technol. Aliment. 2008, 7, 5-20.

39. Kanjan, P.; Hongpattarakere, T. Prebiotic efficacy and mechanism of inulin combined with inulin-degrading Lactobacillus paracasei I321 in competition with Salmonella. Carbohydr. Polym. 2017, 169, 236-244. [CrossRef]

40. Chuah, L.O.; Foo, H.L.; Loh, T.C.; Mohammed Alitheen, N.B.; Yeap, S.K.; Abdul Mutalib, N.E.; Abdul Rahim, R.; Yusoff, K. Postbiotic metabolites produced by Lactobacillus plantarum strains exert selective cytotoxicity effects on cancer cells. BMC Complement. Altern. Med. 2019, 19, 114. [CrossRef]

41. Likotrafiti, E.; Valavani, P.; Argiriou, A.; Rhoades, J. In vitro evaluation of potential antimicrobial synbiotics using Lactobacillus kefiri isolated from kefir grains. Int. Dairy J. 2015, 45, 23-30. [CrossRef]

42. Chaiyasut, C.; Pattananandecha, T.; Sirilun, S.; Suwannalert, P.; Peerajan, S.; Sivamaruthi, B.S. Synbiotic preparation with lactic acid bacteria and inulin as a functional food: In vivo evaluation of microbial activities, and preneoplastic aberrant crypt foci. Food Sci. Technol. 2017, 37, 328-336. [CrossRef]

43. Shokryazdan, P.; Jahromi, M.F.; Liang, J.B.; Sieo, C.C.; Kalavathy, R.; Idrus, Z.; Ho, Y.W. In Vitro Assessment of Bioactivities of Lactobacillus Strains as Potential Probiotics for Humans and Chickens. J. Food Sci. 2017, 82, 2734-2745. [CrossRef] [PubMed]

44. Pereira, S.A.; Jerônimo, G.T.; da Costa Marchiori, N.; de Oliveira, H.M.; Owatari, M.S.; Jesus, G.F.A.; Garcia, P.; do Nascimento Vieira, F.; Martins, M.L.; Mouriño, J.L.P. Autochthonous probiotic Lactobacillus sp. in the diet of bullfrog tadpoles Lithobates catesbeianus improves weight gain, feed conversion and gut microbiota. Aquac. Nutr. 2017, 23, 910-916. [CrossRef]

45. Jang, H.J.; Song, M.W.; Lee, N.K.; Paik, H.D. Antioxidant effects of live and heat-killed probiotic Lactobacillus plantarum Ln1 isolated from kimchi. J. Food Sci. Technol. 2018, 55, 3174-3180. [CrossRef] [PubMed]

46. Jung, J.H.; Kim, S.J.; Lee, J.Y.; Yoon, S.R.; You, S.Y.; Kim, S.H. Multifunctional properties of Lactobacillus plantarum strains WiKim83 and WiKim87 as a starter culture for fermented food. Food Sci. Nutr. 2019, 7, 2505-2516. [CrossRef]

47. Cheon, M.J.; Lim, S.M.; Lee, N.K.; Paik, H.D. Probiotic Properties and Neuroprotective Effects of Lactobacillus buchneri KU200793 Isolated from Korean Fermented Foods. Int. J. Mol. Sci. 2020, 21, 1227. [CrossRef]

48. Aziz, G.; Fakhar, H.; Rahman, S.; Tariq, M.; Zaidi, A. An assessment of the aggregation and probiotic characteristics of Lactobacillus species isolated from native (desi) chicken gut. J. Appl. Poult. Res. 2019, 28, 846-857. [CrossRef]

49. O’Donnell, M.M.; Harris, H.M.B.; Lynch, D.B.; Ross, R.P.; O'Toole, P.W. Lactobacillus ruminis strains cluster according to their mammalian gut source. BMC Microbiol. 2015, 15, 80.

50. Pisano, M.B.; Viale, S.; Conti, S.; Fadda, M.E.; Deplano, M.; Melis, M.P.; Deiana, M.; Cosentino, S. Preliminary evaluation of probiotic properties of Lactobacillus strains isolated from Sardinian dairy products. Biomed. Res. Int. 2014, 2014, 286390. [CrossRef]

51. Ng, S.Y.; Koon, S.S.; Padam, B.S.; Chye, F.Y. Evaluation of probiotic potential of lactic acid bacteria isolated from traditional Malaysian fermented Bambangan (Mangifera pajang). CYTA J. Food 2015, 13, 563-572.

(C) 2020 by the authors. Licensee MDPI, Basel, Switzerland. This article is an open access article distributed under the terms and conditions of the Creative Commons Attribution (CC BY) license (http://creativecommons.org/licenses/by/4.0/). 